\title{
Political Prisoners in the U.S. Valley of Death Zolo Agona Azania
}

People who come out of prison can build up the country: Misfortune is a test of people's fidelity. Those who protest at injustice are people of true merit.

- Ho Chi Minb

$\sigma$ ome seemingly respectable people enjoy sensational skulduggery of tragic love triangles and detective crime statistics; they find invidious pleasure in revulsion. Executions are used as a burnt offerings, and the condemned are stigmatized as visible targets of hatred and public scorn. The relation between crime and social factors is indisputable. People in free society are intensely angered by downsizing, factory automation, and technologies that have eliminated hundreds of thousands of jobs, leaving only work servicing the rich. They are able to direct some of their resentment and pent-up frustrations at the executed prisoner. Thus, capital punishment fulfills its role in a vicious cycle.

Most of the people on death rows are social prisoners, who were neither politically conscious, nor politically active prior to their arrest and conviction. Social prisoners are held up as throwaway people and, as such, are ruthlessly fed into the grinding jaws of an inflated, overtaxed, depressed political economy. So the withholding of evidence, or illegally suppressing favourable evidence from people on trial for their lives is no big deal.

Every time you open your mouth to speak and the truth comes out, a growing number of people will despise you. Those in positions of public trust, such as haughty politicians, corrupt police, corporation heads, and the conveyers of licentious influences in government harbour unrelenting disdain for those who throw light on their questionable dealings. The multi-billion-dollar, actionpacked movie and broadcast industries are fuelled by extreme ravishment. Whether it is comedy, cartoon, drama, or mystery, orchestrated violence attracts the huge crowds. It is good when bundles of money are raked in as profit. The production and distribution of carnal degradation is justified by the return of vast revenue. Money makes it right. If money cannot be made, then it is bad. Build more prisons, but please leave the corruption alone.

What sense does it make for politicians to spend millions of dollars campaigning for public office, work that only pays a salary of about $\$ 95,000$ per year? Political science has become an art form, and professional politicians 
have made it into a lucrative business. More millionaire candidates are spending whatever it takes to win a seat in political office. And those who are obsessed with state-sanctioned murder, every one of them by the shameless measure of endeavour for direct power to increase their personal treasure, is reflective of the economic class characteristics of this particular form of political government. Their exaggerated promises of prosperity for all - glibly arranged by speechwriters - will predictably fail every time because they are based upon deception and prestige.

Children in particular want to learn the truth, to be good, and do good, but they do not have a choice about what they hear and see. Children grow and develop at the contours of their social reality. Wars are necessary sometimes. It is necessary to cut down some types of trees here and there. Be that as it may, some things that are done in the name of profit and progress are uncalled for. We may like some things that are bad for us, and hate that which is good for us. The bottom line is that human beings worldwide are interrelated and interconnected with one another, and with the earth and universe. There is not one thing that we can do to the community or to the environment that we do not also do to ourselves.

Childhood is such a brief period of time. Children need stability. Their lives have been disrupted by no fault of their own. Children do not have a choice of when or if they will be conceived and born into this world. Children do not have a choice of who their parents will be. Children do not have a choice if they are sexually and psychologically abused. Negligent infliction of emotional harm has lingering adverse effects on a child's impressionable mind. Prisons and juvenile delinquent centres are bursting at the seams with children and adults who were reared in abusive homes and corrupt environments. The profound irony in this is that the dehumanizing prison and jail environment compounds the malaise.

The atrophy of our youth is ubiquitous. The malaise is not confined to any single ethnic milieu. The problem of crime and economic underdevelopment encompasses every region in the country. Children sometimes steal when they're emotionally distressed, as do adults. But children are not the problem. Our children are the future. If our beloved children are destroyed, there will be no future. With the removal of the Berlin Wall in Germany, the breakup of the former Soviet Union, with the end of the ill-fated East-West Cold War, as well as the phoney war on drugs, the youth of our nation have become targeted for a type of war. Devout proponents of capital punishment and private prisons 
routinely mention the expectations of children in the same breath as future crime trends. Criminal behaviour is not a genetic trait associated with any particular people, but it is wrongfully attributed to the youth of ethnic minority groups. This supposition is not a legitimate point of view, and the pro-status quo analysts know it.

When the economic picture is bleak and jobs scarce, crime, more often than not, becomes a twisted option to many. The violence associated with unemployment and crime is, indeed, a public health problem. I think that jobs and income should always be a central topic of discussion in society until the problem of unemployment and poverty is resolved. Gainful employment and self-esteem are interrelated. Public health problems are often perceived as crime issues and law enforcement concerns. People who are mentally or emotionally depressed sometimes act out their depression by constantly doing risky things that threaten their lives, such as injecting drugs into their veins for pleasure, or driving recklessly. The repeated dangerous risks in the quest for perilous excitement are actually symptoms of a deeper psychological psychosis, bordering on the verge of suicide in a rush to blot out their painful feelings.

Depression is the debilitating emotions of anger or sadness turned inward. Relief from severe depression does not come through the vehicle of false beliefs and deviant social trends. The right and proper way is not always the most tried and popular way. More often than not, the straight way is rugged and narrow. The good does not always come easy, while the bad usually does. No matter how many afflictions you may have suffered, taking your frustrations out on others will never solve the problem. A particular difficulty is not unique to you only. Other people similarly situated, or worse, have experienced difficulties handling various personal problems. The voluntary intoxication of your mind will never cause your family problems or personal predicaments to go away. Whenever you come back to your senses, these same problems, and more, will be waiting for you.

The drug culture causes people to be fearful, unduly suspicious, and mistrustful of one another. I have a younger brother who flipped out on illicit drugs and alcohol and is now incarcerated. Similarly, I also have a younger sister who is strung out on mind-altering substances. I have not heard from her in years. I am not sure if she is alive or dead. Nonetheless, if I were not imprisoned, I would get her into a detox hospital. Her moral self-esteem would be restored. Her distress in body and mind is not atypical. I do not use dope, smoke dope, or sell dope. And I am not alone with this personal pain. 
The social ills of the collective human family are the mirror image of a people's wretched socio-economic conditions. We have to, and we shall without failure, clean house and disinfect our own community for renewed community development. I do not make any apology for advocating self-reliance. There is a better way. A change is going come. Something momentous is occurring when a people begin to wake up, pick up their lost dignity, and cleanse themselves from the inside out. Freedom is a struggle every step of the way. No matter how difficult the struggle may be, we must continue to push and pull upward and forward.

New Afrikan is my nationality. This is who I am. Al-Islam is my way of life. My so-called radical political and religious beliefs, which I refuse to renounce, scared the throwback conservatives in the city of Gary. Knowledge gives one responsibility. This I had, but the simple fact that I might be able to turn young, misguided people's lives from self-destruction to self-construction was even more frightening to the city of Gary's conservative power system. It is diametrically opposed to any political activity that does not coincide with its political agenda, for to do so would inevitably unsettle the status quo. Thus, the promotion of the crime epidemic is being used on every level of this society as a tool to justify our oppression. What has happened to me could easily happen to you or your loved ones. Do not think it cannot, because that is when it will probably happen.

Zolo Agona Azania is incarcerated as prisoner \#4969 in Indiana State Prison, P.O. Box 41, Michigan City, Indiana 46361-0041, U.S.A. His spirit is strong and resolute for human rights and dignity. 